\title{
Improving Peer Relations of Elementary School Students through a School Gardening Program
}

\author{
Seong-Sil Kim ${ }^{1}$, Sin-Ae Park ${ }^{2,3}$, and Ki-Cheol Son ${ }^{1,2}$
}

ADDITIONAL INDEX wORDs. horticultural therapy, peer relationships, school bullying, sociality, socio-horticulture

\begin{abstract}
SUMMARY. For older elementary school students, amicable peer relationships are important to meeting developmental challenges, such as socialization. Thus, in this study, the effectiveness of a school gardening program to promote positive social relationships among elementary school students was assessed. The participants in this study were fifth and sixth grade students from four elementary schools in Wonju, South Korea. The experimental and control groups consisted of 123 students each (total 246) from fifth and sixth grade classrooms. The gardening program included a range of activities, such as sowing seeds and harvesting produce, and was designed to improve peer status, peer relations, and sociality. The program was embedded in the school curriculum; sessions were 90 minutes per week for 10 weeks from 16 April through 25 June 2012. The results revealed the school gardening program brought about meaningful differences in both persistence of friendship $(P=0.04)$ and adaptability between friends $(P=0.03)$, which were subcategories of peer relationships, in the experimental group. There were also significant improvements in sociality $(P<0.001)$ and its various subcategories, especially in law-abiding $(P<0.001)$ and collaboration $(P<0.001)$. Finally, the peer status results showed that there was significantly a greater increase in the peer status after the school gardening program, but there was no significant change in the control group. In conclusion, the school gardening program for elementary school students had a positive influence on peer relationships, sociality, and peer status. Implementing a garden program in schools will effectively contribute to the improvement of social relationships among elementary school students.
\end{abstract}

$\mathrm{H}$

umans form relationships with other people in their natural environment, i.e., society. Humans acquire values, behavior patterns, and the knowledge required by society in a process known as socialization (Park, 1988). The term "sociality" refers to the aspects of human nature shaped through socialization. Sociality is not gained spontaneously, but requires experiences in social environments (Park, 1988). Childhood is a critical period for the development of sociality, and much of this development occurs when the child's social environment expands from just their immediate family and neighbors to their school (Choi, 2009). Children who have good relations with friends and teachers are less likely to become juvenile delinquents or social misfits compared with

This paper was supported by the SMART Research Professor Program of Konkuk University.

${ }^{1}$ Department of Horticultural Therapy, Graduate School of Agriculture and Animal Science, Konkuk University, Seoul 143-701, South Korea

${ }^{2}$ Department of Environmental Health Science, Konkuk University, Seoul 143-701, South Korea

${ }^{3}$ Corresponding author. E-mail: sapark42@konkuk. ac.kr. the children who cannot easily adjust to a peer group (Kim, 2011).

Peers can be defined as companions in an equal position (Garvey, 1984), or persons who are socially equal (Lewis and Rosenblum, 1975), and thus are in a socially horizontal position, which allows a child to freely try out new beliefs and actions. Therefore, sociality, which is difficult to acquire in hierarchal relationships, can be learned though peer relations. Additionally, children interact and play diverse roles in social situations with peers. Thereby, children are afforded with the opportunity to practice and learn various basic skills necessary for successful social relations (Choi, 2002).

Peers have various functions, according to Song (1995). First, peers become key role models for each other. In many situations, children observe, copy, and internalize the behaviors of peers. In addition, by observing the success and failure of peers, children discern how to behave and how not to behave. Second, peers become important reinforcers for one another. In particular, a compliment or criticism from a child who plays a dominant role in a class has a strong impact during the elementary school period. A culture that reinforces positive behaviors in class and encourages children to help each other and cooperate facilitates positive social development. Third, peers are models for social comparison because they are a standard by which children can evaluate themselves. Beginning in preschool, children compare and evaluate their character, value, and ability through interactions with their peer group. This type of evaluation becomes the basis of the formation of self-image and self-esteem. Fourth, peers provide social support, which refers to real and psychological support given by another person in a difficult situation. At times, peers give a type of comfort that adults are not able to provide and become social supporters, not unlike parents.

Children with close peers are able to talk about their worries and discuss solutions, which can help alleviate psychological damage resulting from peer bullying. Moreover, children may receive advice regarding ways to deal with conflicts and risks (Bukowski et al., 1994). However, inappropriate interaction with peers can result in social isolation and reduce the chances to develop and implement social skills. Children with poor peer interaction skills may form negative concepts about themselves and society, which may have a longterm impact on social adaptation (Jeong, 2010). Therefore, forming positive peer relations is essential to children's development of sociality, and has long-lasting effects.

The term "peer status" refers to the position of a child within a peer group based on levels of social acceptance, social preference, and attraction or rejection (Rhee, 1999). Coie et al.(1982) used a peer nomination instrument to identify five categories of peer status: popular, controversial, ordinary, ignored, and rejected. Children who are rejected typically exhibit the most problems. Such children often manifest antisocial behaviors after experiencing social isolation, and they have few opportunities to acquire social skills. The level of acceptance of a child in a peer group is closely related to the child's overall adaptation and sociality development. Furthermore, it profoundly affects the emotional development of the child, including the 
skills necessary to manage stress (Cho, 2012). Therefore, a multilateral approach toward improvement in peer status is necessary.

Plants have been used for refreshing and cultivating the mind and body, as they not only provide humans with clothes, food, and housing but also offer joy, peace, and the opportunity to rest (Son et al., 2006). Horticultural activities that take advantage of these benefits of plants enable students to interact with teachers and classmates, becoming cooperative, active, and independent without relying solely on verbal instructions (Choi, 2007a). Horticulture may also convey a sense of accomplishment and success to children because the tasks associated with growing plants are not always easily accomplished (Kim, 2006). In addition, as the tasks require much teamwork, cooperation with peers is necessary and encouraged (Yoon, 2001). Horticulture activities are conducive to effective interactions among peers that allow self-expression and encourage the acceptance of others' decisions (Song, 2008). Furthermore, horticultural activities help children develop a sense of belonging and increase their selfconfidence and self-esteem (Song, 2002). Moreover, horticulture may alleviate feelings of tension, despair, and aggressiveness, while providing opportunities for self-expression. In addition, Waliczek et al. (2001) reported that participation in school gardening activities improved attitudes toward school, especially in female students and interpersonal relationships in seventh grade students among all grades. School-age children are at a critical stage in the development of sociality, and because peers are so important to this development of sociality, this study was conducted to examine the impact of a school gardening program on peer relations, peer status, and sociality in older elementary school students.

\section{Materials and methods Participants}

This study was conducted with 246 fifth and sixth grade students from four elementary schools (designated $\mathrm{B}, \mathrm{C}, \mathrm{H}$, and $\mathrm{M}$ ) located in Wonju, South Korea. The Wonju Office of Education sent official letters of application to all 49 elementary schools in Wonju City. The inclusion criteria for schools were 1 ) not having a garden, but an available plot of land, $\approx 70 \mathrm{~m}^{2}$, which could be used for gardening and 2) not being in a provincial town unit. This last criterion eliminated schools in areas such as Eup and Myeon, which are rural and have a natural environment, because the students could have been exposed to gardening activities through their residential environment. Applications from 10 elementary schools were received in mid-Mar. 2012; four schools met the prerequisites. Two classes (one experimental group class, one control group class) were selected from each of these schools. The average age of students was (mean $\pm \mathrm{SD}$ ) $12.7 \pm 0.4$ years; the gender ratio of experimental and control groups was $\approx 50: 50$. At the completion of the pre- and posttest, each student was given school supplies as an incentive.

\section{School gardening program period and environment}

The school gardening program consisted of 10 weekly sessions of 90 min each during regular class hours from 16 April through 25 June 2012. The program began in April when the temperature for growing crops had stabilized, and the end of the program coincided with the end of the semester so students would not have a break in their experiences, thus maximizing the sense of achievement gained through continuous gardening activities. The program was conducted in the gardening plots, sized $\approx 70 \mathrm{~m}^{2}$, and classrooms in each school. Before the start of the gardening programs in the schools, three primary (master's students of horticultural therapy) and four assistant instructors (students of horticultural therapy at a lifelong education center at a university) were informed of the teaching objectives and activities for each session. A primary and assistant instructor led the weekly gardening program at each school.

For the school gardening activity program, students were placed into groups of five to six children. One week before the start of the program in an orientation, a rating of peer status was obtained [Coie et al. 1982 (see the Assessments section for more detailed information)]; children were assigned a status based on this rating (popular, controversial, ordinary, ignored, or rejected). Each group included a popular, controversial, ordinary, ignored, and rejected child.

\section{Development of the school gardening program}

SELECTION OF FACTORS ASSOCIATED WITH THE IMPROVEMENT OF SOCIAL RELATIONS. A literature search was conducted using a Research Information Sharing Service (Korea Education and Research Information Service, Daegu, South Korea) search engine; 48 papers related to the influence of self-esteem on sociability and socially friendly behaviors were selected. From these papers, several factors were identified to enhance selfesteem (Song, 1993) and to encourage socially friendly behaviors (Lee, 2001), including self-understanding (Do, 2008) and expression (Choi, 2007b), sense of achievement (Kim, 2012), sense of power (Jang, 2012), sense of belonging (Yun, 2011), sense of intimacy (Lee, 2012), communication (Kim, 2013), cooperation (Kim, 2013), sense of responsibility (Hwang, 2012), and reinforcement (active listening, compliments, encouragement) (Jang, 2012). Each of these factors was considered in the development of the gardening program.

DEVELOPING THE SCHOOL GARDENING ACTIVITIES. The program consisted of 10 sessions within one semester, all centered on plant cultivation, such as creating garden beds, planting crops, managing crops, harvesting produce, and using the plants for cooking and crafts (Table 1). Seasonal plants that could capture the interest of children were chosen for this program. The seeds selected were potato (Solanum tuberosum), kidney bean (Phaseolus vulgaris), lettuce (Lactuca sativa), chicory (Cichorium intybus), radish (Raphanus sativus), kohlrabi (Brassica oleracea ssp. gongylodes), chinese cabbage (Brassica campestris ssp. pekinensis), and pak choi (Brassica chinensis).

The objectives of the gardening activities were to improve social relationships (i.e., peer relations, peer status, and sociality) in fifth and sixth grade elementary school students. Various social factors such as self-esteem, cooperation, self-understanding, expression, sense of achievement, sense of power, sense of belonging, sense of intimacy, communication, responsibility, and reinforcement selected by searching literature were embedded 
Table 1. Garden activity type and summary of the 10-session school gardening program to promote positive social relationships among elementary school students.

\begin{tabular}{|c|c|c|}
\hline Session & Activity type & Summary of the activity \\
\hline 1 & Making a flower bed & $\begin{array}{l}\text { Cultivating and fertilizing a garden plot, } \\
\text { creating a group nickname }\end{array}$ \\
\hline 2 & $\begin{array}{l}\text { Making a flower bed, } \\
\text { planting }\end{array}$ & $\begin{array}{l}\text { Plowing furrows and covering the } \\
\text { garden plot with polyethylene film, } \\
\text { planting transplants }\end{array}$ \\
\hline 3 & Planting & Planting transplants, sowing seeds \\
\hline 4 & Planting, maintenance & Planting transplants, watering \\
\hline 5 & Maintenance & $\begin{array}{l}\text { Making natural agricultural } \\
\text { pesticides and natural fertilizers }\end{array}$ \\
\hline 6 & Maintenance & $\begin{array}{l}\text { Applying the natural pesticides and } \\
\text { fertilizers in the garden plot, watering }\end{array}$ \\
\hline 7 & Harvesting, planting & $\begin{array}{l}\text { Harvesting produce, weeding, planting } \\
\text { transplants, sowing seeds }\end{array}$ \\
\hline 8 & Utilization & Weeding, cooking, tasting \\
\hline 9 & Harvesting, planting & Harvesting produce, planting transplants \\
\hline 10 & Harvesting & Harvesting produce, cleaning the garden plot \\
\hline
\end{tabular}

in the activities of each session to improve social relations. Each activity in a session was developed by the cooperation of experts in the field of horticultural therapy, horticultural education, and horticulture. The activity consisted of the plant cultivation activity and cooperation processes and was intentionally modified to improve social relations by including the factors related to social relations such as selfesteem, sense of achievement, cooperation, etc. that were identified in the literature search (Table 2).

Each group, whose members were chosen according to their peer status, had to meet the intended objectives for these activities in each session as a group. The sessions were organized into three sections: introduction, development, and wrap up. The average time spent for each session was 15,60 , and $15 \mathrm{~min}$, respectively. During the introduction, the objective for each session was presented and students were reminded of the previous activity. In addition, to capture the students' interest, a description of the day's activities was included. To encourage group unity, each activity had a group mission, and an incentive was provided at the end of each session. During the development section, the students carried out horticultural activities in the garden according to the day's targets, which were designed to positively influence the development of social relations using the factors identified in the literature search. It was also believed that successfully executing the day's tasks would result in a sense of achievement (Shin, 2012). In the wrap-up stage, the students cleaned the horticultural tools and the garden area before moving to a classroom or to a compartmentalized area to complete and present group activity papers. In this section of the session, students were given the opportunity to provide positive feedback to each other, express their thoughts and feelings to classmates, and listen and empathize with friends, all of which are activities that encourage the offering of social reinforcements (Seo, 2012).

For example, the gardening activity of the sixth session was called "Now the garden needs..." (Table 2), and the objective of the activity was to add natural fertilizers and pesticide to the garden and share the positive things the students found out about their group members during the gardening activities. During the introduction stage of the sixth session, the students greeted each other and were seated according to their groups to encourage a sense of belonging. Explaining how to make the fertilizers and pesticide drew students' interest. During the development stage, the group members were told to discuss and divide task responsibilities in the garden. The students then worked together to apply fertilizer and pesticide, thus gaining a sense of achievement. During the wrap-up stage, the students wrote about the good points of their group members on an activity sheet; this exercise was developed to enhance the sense of belonging and intimacy. The instructors selected the best group of the day to provide positive reinforcement by subjective evaluation during the session. The groups that were not selected were informed that they would have another opportunity to be selected next class. Finally, a brief discussion of the next session's gardening activities secured the students' interest.

\section{Assessments}

To examine the effect of the school gardening program on the social relations development of participants, all students completed questionnaires on peer relations, peer status, and sociality before and after the program. The preevaluation was conducted 1 week before the gardening program began. The postevaluation was conducted in each classroom during regular class hours 1 week after the program ended. The children answered the questionnaires individually.

The peer relations scale, created by $\mathrm{Kim}$ (1989) and revised by Kim (2005), is composed of 20 items in four subscales: presence and reliability of friends, persistence of fellowship, adaptability among friends, and communal living with friends. Students responded to each item on a fivepoint Likert scale according to their agreement or disagreement with the statements (e.g., "I don't make friends easily"). Total scores ranged from 20 to 80 points. Higher scores were indicative of positive peer relations. In this study, the Cronbach's alpha was 0.89 .

To measure peer status, the nomination scheme of Coie et al. (1982) was used. This scale has been previously used in the education field to measure peer relations (Cho, 2012; Choi, 2004; Kang, 2009). This method requires children to anonymously name three classmates they want to sit with and three classmates with whom they do not want to sit. The number of positive nominations and negative nominations from peers are standardized $[\mathrm{Z}$ score $=$ (original score - average score)/standard deviation], followed by the categorization of the respective positive nomination score and negative 
Table 2. Example of a session curriculum (Session 6) in the school gardening program to promote positive social relationships among elementary school students.

\begin{tabular}{|c|c|c|}
\hline Title & \multicolumn{2}{|l|}{ Now the garden needs } \\
\hline Objectives & $\begin{array}{l}\text { Tend the garden; spray agricultural pesticide, apply fertilizers, thin ou } \\
\text { that were realized by carrying out teamwork in the garden. }\end{array}$ & press merits of the group members \\
\hline Procedures & Contents & Social factors \\
\hline
\end{tabular}

nomination score. The social preference score is derived by subtracting the negative nomination standard score from the positive nomination standard score (social preference score $=$ positive nomination score - negative nomination score), and the social impact score is calculated by adding the positive and negative nomination scores (social impact score $=$ positive nomination score + negative nomination score). According to the social impact score, the peer status of children was categorized into popular, controversial, ordinary, ignored, and rejected and scored as $1,2,3,4$, and 5 , respectively, by Coie et al. (1982).

To assess sociality, we used Lee's (1997) revised scale, which is based on Jung's (1971) scale for assessing the character and sociality of elementary school students. This scale consisted of 30 items in four subscales: law-abiding, cooperation, extrovert, and independence. Participants' response to each question is rated on a three-point Likert scale. Total scores ranged from 30 to 90 . A higher score indicated higher sociality. The Cronbach's alpha in this study was 0.96 .

\section{Data analysis}

To identify changes in peer relations, peer status, and sociality engendered by the school gardening program, SPSS (version 19.0; IBM Corp., Armonk, NY) was used to conduct paired $t$ test and analysis of covariance (ANCOVA) at $P<0.05$. The covariate in the ANCOVA was the preliminary value. Data from 102 students in the experimental group and 109 in the control group were analyzed after incomplete questionnaires were removed for data analysis. 


\section{Results and discussion}

EFFECTS OF THE SCHOOL GARDENING PROGRAM ON PEER RELATIONS. The comparison between control and experimental groups for peer relations revealed statistically significant differences in the subcategories of persistence of fellowship $(P<0.001)$ and adaptability among friends $(P<0.001)$ (Table 3$)$.

These results are in accordance with prior research by Kim (2006), which revealed that cultivating one potted plant per person and group horticultural activities centered on the establishment and maintenance of a garden enhanced the sense of community and had a positive impact on peer relations. In addition, Choi (2007a) reported that after 12 sessions of group horticultural activities, peer relations improved and spontaneous cooperation and concessions among children were observed. Shin's (2013) results are also similar; communication, which is the basis for interpersonal relationships, increased after 12 sessions of classroom cultivation activities.

In this study, students compromised and cooperated to reach a common goal, which resulted in improvements in trust and relations with peers. In particular, the gardening program was effective in building

Table 3. Between-subjects tests of postprogram effects on social relationships to promote positive social relationships among elementary school students.

\begin{tabular}{llrrrrr}
\hline Items $^{\mathbf{z}}$ & Source & Sum of squares & df & Mean square & F value & $P^{\mathbf{y}}$ \\
\hline Presence of friends & Covariate & 63.84 & 1 & 63.84 & 161.90 & $<0.001$ \\
and reliability & Group & 0.46 & 1 & 0.46 & 1.39 & 0.24 \\
& Error & 69.19 & 208 & 0.33 & & \\
Persistence of the & Covariate & 23.22 & 1 & 23.22 & 82.64 & $<0.001$ \\
fellowship & Group & 1.22 & 1 & 1.22 & 4.33 & 0.04 \\
& Error & 58.43 & 208 & 0.28 & & \\
Adaptability among & Covariate & 33.09 & 1 & 33.09 & 141.28 & $<0.001$ \\
friends & Group & 1.13 & 1 & 1.13 & 4.83 & 0.03 \\
& Error & 48.71 & 208 & 0.23 & & \\
Communal living & Covariate & 0.51 & 1 & 0.51 & 0.59 & 0.45 \\
with friends & Group & 0.25 & 1 & 0.25 & 0.28 & 0.60 \\
& Error & 179.8 & 208 & 0.86 & & \\
Peer-relation & Covariate & 27.05 & 1 & 27.05 & 134.83 & $<0.001$ \\
& Group & 0.72 & 1 & 0.72 & 3.57 & 0.06 \\
& Error & 41.74 & 208 & 0.20 & & \\
\hline
\end{tabular}

${ }^{2}$ The peer relations scale is a five-point Likert scale composed of 20 items divided into four subscales: presence and reliability of friends, persistence of fellowship, adaptability among friends, and communal living with friends (Kim, 2005 ). Total scores ranged from 20 to 80 points. Higher scores indicated more positive peer relations.

ydjusted for pretest values as covariate by analysis of covariance at $P<0.05$

trust and maintaining friendship (persistence of fellowship) and increasing popularity and trust (adaptability among friends) through interaction, cooperation, and finding new and positive facets of previously distant friends. On the other hand, 10 seswere not enough to obtain in the levels of subcategories "presence of and reliability of friends" and "communal living with friends," which required sponses in developing and maintaining friendships.

EFFECTS OF THE SCHOOL GARDENING PROGRAM ON PEER Arus. Table 4 shows the peer status before and after the school the control group, there was no significant change in peer status. On the other hand, in experimental group, there was cantly a greater increase in pee status after the school gardening program (Table 4).

These results indicate that the school gardening program, which included participation in horticultural activities from sowing to harvesting and working with group members, tively affected peer status. This result is in line with research demonstrating that children who participate

Hortlechnology · April 2014 24(2) continuously in competitive team sports activities learn social skills through interactions with other children, which helps to improve peer status (Lee, 2008). In addition, it is consistent with the results of a study that concluded that social group activities in elementary school physical education classes positively affect the peer status of children (Cho, 2012).

These results suggest that when an ignored child enters a new peer group, the ignored status is not maintained (Song, 2007). A social group encourages active communication among children, resulting in the formation of new social relationships. A child is able to have more opportunities to try out positive developments in social relationships (Cho, 2012). The school gardening program contributed to the development of positive relations and the reduction of negative relations among peers.

EFFECTS OF THE SCHOOL GARDENING PROGRAM ON SOCIALITY. The preliminary value of sociality was controlled as a covariate to compare how sociality changed posttreatment between individuals of the control and experimental groups. The change in sociality was significantly higher in the experimental group $(P<0.001)$. The law-abiding $(P<0.001)$ and cooperation $(P<0.001)$ subcategories of sociality also significantly differed between the experimental group and control groups. This demonstrates that the school gardening program-where children follow the instructions of teachers, work together, and communicate to effectively carry out tasks - is highly effective in enhancing sociality (Table 5 ).

A cultivation activity during which children discuss and help each other is an effective means of improving $\mathrm{CO}^{-}$ operation (Yoon, 2001). Moreover, during the horticultural activities, children's law-abiding spirits are fostered because they feel compelled to fulfill their responsibilities during the activities and clean up (Kim, 2006). This is in accordance with existing research that concluded that cultivating vegetables (Kim, 2004), a work-oriented education program (Bae and Ryu, 2005), and group horticulture activities (Kim, 2006) are effective in improving sociality. However, the detailed activities of this program were primarily implemented through the guidance and directions 
Table 4. Peer status rating for control $(N=109)$ and experimental groups $(N=$ 102) before and after the gardening program to promote positive social relationships among elementary school students.

\begin{tabular}{lccr}
\hline & \multicolumn{1}{c}{ Pretest } & Posttest & \\
\cline { 2 - 3 } Group & \multicolumn{1}{c}{ Peer status rating $(\text { mean } \pm \text { SD })^{\mathbf{z}}$} & $P^{\mathbf{y}}$ \\
\hline Control & $2.97 \pm 1.36$ & $2.95 \pm 1.41$ & 0.89 \\
Experimental & $3.05 \pm 1.28$ & $2.72 \pm 1.40$ & 0.01 \\
\hline
\end{tabular}

${ }^{z}$ Children were required to anonymously name three classmates they wanted to sit with and three classmates with whom they did not want to sit. The number of positive nominations and negative nominations from peers were standardized $[\mathrm{Z}$ score $=($ original score - average score $) /$ standard deviation $]$, and then categorized as positive or negative. The social preference score was derived by subtracting the negative nomination standard score from the positive nomination standard score (social preference score $=$ positive nomination score - negative nomination score), and the social impact score was calculated by adding the positive and negative nomination scores (social impact score $=$ positive nomination score + negative nomination score). Peer status was categorized into popular, controversial, ordinary, ignored, and rejected and scored as 1, 2, 3, 4, and 5, respectively (Coie et al., 1982).

y Probability using paired $t$ test analysis.

Table 5. Between-subjects tests of postprogram effects on sociality to promote positive social relationships among elementary school students.

\begin{tabular}{llrrrrc}
\hline Items $^{\mathbf{z}}$ & Source & Sum of squares & df & Mean square & F value & $P^{\mathbf{y}}$ \\
\hline Law-abiding & Covariate & 0.00 & 1 & 0.00 & 0.00 & 0.99 \\
& Group & 33.16 & 1 & 33.16 & 88.84 & $<0.001$ \\
& Error & 77.63 & 208 & 0.37 & & \\
Cooperation & Covariate & 0.06 & 1 & 0.06 & 0.18 & 0.67 \\
& Group & 19.20 & 1 & 19.20 & 61.97 & $<0.001$ \\
& Error & 64.44 & 208 & 0.31 & & \\
Extrovert & Covariate & 5.95 & 1 & 5.95 & 83.10 & $<0.001$ \\
& Group & 0.00 & 1 & 0.00 & 0.06 & 0.80 \\
& Error & 14.90 & 208 & 0.07 & & \\
& & & & & & \\
Independence & Covariate & 7.28 & 1 & 7.28 & 67.43 & $<0.001$ \\
& Group & 0.03 & 1 & 0.03 & 0.25 & 0.62 \\
& Error & 22.46 & 208 & 0.11 & & \\
Sociality & Covariate & 1.90 & 1 & 1.90 & 20.70 & $<0.001$ \\
& Group & 2.79 & 1 & 2.79 & 30.43 & $<0.001$ \\
& Error & 19.06 & 208 & 0.09 & & \\
\hline
\end{tabular}

${ }^{2}$ The sociality scale is a three-point Likert scale that consists of 30 items categorized into four subscales: lawabiding, cooperation, sociability, and independence (Lee, 1997). Total scores ranged from 30 to 90 . A higher score indicated higher sociability.

yAdjusted for pretest values as covariate by analysis of covariance at $P<0.05$

of instructors. Thus, opportunities to form extensive relations with peers in the class were relatively limited. There were no significant changes in the subcategories of independence and sociality. Therefore, free and nonstructured programs, which are a form of self-directed learning by students (Han et al., 2013), need to be developed in which children implement the activities and solve issues themselves rather than through the enforcement or assessment of instructors (Choi and Han, 2012).

In conclusion, the school gardening program for fifth and sixth grade elementary school students was effective in enhancing peer relations and sociality, and engendering changes in peer status. By introducing social factors such as communication, cooperation, sense of responsibility, and reinforcement (consisting of active listening, compliments, and encouragement) into the program, socially positive results were obtained by encouraging spontaneous friendly behaviors for the benefit of others (Bar-Tal, 1976). In addition, to improve self-esteem, which is a vital element of peer status (Song, 2002), several social factors in gardening curriculum, such as self-understanding, self-expression, and sense of achievement and power, belonging, and intimacy were embedded in the activities for each session.

Since this program was limited to fifth and sixth graders, and was conducted only from April to June in
Wonju, additional studies are necessary. Studies of specific plants and potential horticultural activities across seasonal changes and regional characteristics are required. The period of the program needs to be extended so that the opportunity to improve social relationship skills encompasses all four seasons. Furthermore, the program needs to include different levels of activities for various age groups. The intervention of instructors should be minimized to become passive and nondirectional. In summary, additional research to develop nonstructured school gardening activities in which children spontaneously take the lead in activities is necessary.

\section{Literature cited}

Bae, S.G. and C.S. Ryu. 2005. The effect of laborious working learning programs on the elementary school students sociality development. J. Korean Practical Arts Educ. 18:225-236.

Bar-Tal, D. 1976. Prosocial behavior: Theory and research. Halsted Press, New York, NY.

Bukowski, W., B. Hoza, and M. Boivin. 1994. Measuring friendship quality during pre-and early adolescence: The development and psychometric properties of friendship qualities scale. J. Soc. Pers. Relat. 11:471-484.

Cho, Y.W. 2012. The effects on the group cohesion and peer groups by the composition of social groups in physical education of elementary school. Korea Natl. Univ. Educ., Chungwon, Korea, MS Diss.

Choi, H.S. 2004. Study on the social maturity and peer status of gifted children. Daejeon Univ., Daejeon, Korea, MS Diss.

Choi, I.H. 2007a. Effects of horticultural activities on the peer relations and school life satisfaction of elementary students. Dankook Univ., Cheonan, Korea, MS Diss.

Choi, J.K. 2007b. Study of emotional intelligence and emotional regulation of the abused and the general children. Myeong-ji Univ., Seoul, Korea, MS Diss.

Choi, J.Y. 2009. The social skill changes of the elementary school students through the participation in team building activities. Gyeongin Natl. Univ. Educ., Incheon, Korea, MS Diss.

Choi, M.A. and Y.J. Han. 2012. The effects of child-centered group play therapy for improvement on self-esteem and sociality of young children. Korean J. Child Psychotherapy 7:1-26. 
Choi, S.R. 2002. Social dynamics of early childhood classrooms. J. Child. Stud. $8: 59-76$

Coie, J.D., K.A. Dodge, and H. Coppotelli. 1982. Dimensions and types of social status: A cross-age perspective. Dev. Psychol. 18:557-570.

Do, Y.S. 2008. Effect of indoor sand play on the self-esteem and social skills of preschoolers. Ewha Womans Univ., Seoul, Korea, MS Diss.

Garvey, C. 1984. Children's talk. Harvard Univ. Press, Cambridge, MA.

Han, W., Y.J. Kang, and J.N. Kim. 2013. Problem-finding and problem-solving processes under ill-structured scientific problem situation for high school students. Teacher Educ. Res. 52:195-214.

Hwang, J.Y. 2012. The effect on prosocial behavior and self-esteem of young children through caring education using picture book. Chungang Univ., Seoul, Korea, MS Diss.

Jang, J.E. 2012. The influence of family related compliment activity program's existence on forming self-esteem with prosocial skills of early child. Kyunghee Univ., Seoul, Korea, MS Diss.

Jeong, M.J. 2010. Relationships among empathizing, prosocial behavior and peer relationship of elementary childhood. Changwon Natl. Univ., Changwon, Korea, MS Diss.

Jung, B.M. 1971. Personality code. Korean Testing Ctr., Seoul, Korea.

Kang, H.J. 2009. The effect of group art therapy program on the rejected and neglected children's peer relationship. Busan Univ. Educ., Busan, Korea, MS Diss.

Kim, H.K. 2006. Effect of the group horticulture activity on changes in sociality and peer relations of elementary school students. Seoul Natl. Univ. Educ., Seoul, Korea, MS Diss.

Kim, H.T. 1989. Study of the development and the measurement of egoidentity in Korean youth. Chungnam Natl. Univ., Daejeon, Korea, PhD Diss.
Kim, J.H. 2012. The effects of the discussion with picture Books on the selfesteem and prosocial behaviors of preschoolers. Kunsan Univ., Kunsan, Korea, MS Diss.

Kim, K.R. 2004. The effect of vegetable culturing activity on change in sociality of elementary school students. Chinju Natl. Univ. Educ., Jinju, Korea, MS Diss.

Kim, M.J. 2011. The sociometry of elementary school students and study of tendency shown in the network of peers. Busan Natl. Univ. Educ., Busan, Korea, MS Diss.

Kim, Y.E. 2013. Applying problem-based learning (PBL) model to art class and its impact on 3rd grade middle school students' empathic ability. Ewha Womans Univ., Seoul, Korea, MS Diss.

Kim, Y.J. 2005. The effects of solutionfocused brief group counseling program on the isolated elementary school children's peer relationship and self-esteem. Korea Natl. Univ. Educ., Chungwon, Korea, MS Diss.

Lee, J.Y. 2012. The effects of role-playing through realistic fiction on the self-esteem and prosocial behavior of young children. Keimyung Univ., Daegu, Korea, MS Diss

Lee, K.R. 2001. Effects of connection activities on self-respect and social friendly behaviors in parts of ordinary children and children under supervisory accommodation in accordance with the type of the activities. Donga Univ., Busan, Korea, MS Diss.

Lee, S.H. 1997. The effects of the selfexpresson training on forming passive children's self-concept and sociality. Korea Natl. Univ. Educ., Chungwon, Korea, MS Diss.

Lee, S.H. 2008. The effects of selfexpression training program on elementary school students development of sociality. Hannam Univ., Daejeon, Korea, MS Diss.

Lewis, M. and L.A. Rosenblum. 1975. Friendship and peer relations. Wiley, New York, NY.

Park, Y.H. 1988. Social behavior and learning. Educ. Press, Seoul, Korea.
Rhee, U.H. 1999. A study on children's friendship. Child Studies 20(3):77-95.

Seo, Y.A. 2012. The effect about teacher's positive reinforcement and communication to student engagement. Hanyang Univ., Seoul, Korea, MS Diss.

Shin, C.J. 2012. Impact of the participation in marathon on self-achievement. Korea Natl. Univ. Educ., Chungwon, Korea, MS Diss.

Shin, G.S. 2013. The effect of the plant growing activities in class on emotional intelligence and peer relationships. Cheongju Natl. Univ. Educ., Cheongju, Korea, MS Diss

Son, K.C., M.K. Cho, J.E. Song, S.Y. Kim, and S.S. Lee. 2006. Practice of professional horticultural therapy. Coobook, Seoul, Korea.

Song, D.Y. 2008. Effect of the classroom horticultural program on elementary school student's self-esteem and peerrelationships. Cheongju Natl. Univ. Educ., Cheongju, Korea, MS Diss.

Song, M.J. 1995. Developmental psychology. Hakji Press, Seoul, Korea.

Song, S. 2002. An empirical study on children's peer status perception. J. Korean Home Mgt. Assn. 20(2):147-159.

Song, S.H. 1993. The effect of selfexpression training on the peer relation and self-esteem. Dankook Univ., Seoul, Korea, MS Diss.

Song, Y.H. 2007. Peer relationship. Jipmoon Press, Seoul, Korea.

Waliczek, T.M., J.C. Bradley, and J.M. Zajicek. 2001. The effect of school gardens on children's interpersonal relationships and attitudes toward school. Hort Technology 11:466-468

Yoon, S.K. 2001. The effect of the plantculture working on changes in children's personality. Seoul Natl. Univ. Educ., Seoul, Korea, MS Diss.

Yun, C.H. 2011. The relationship between maternal parenting style, pro-social activity and self-esteem. Cheongju Natl. Univ., Cheongju, Korea, MS Diss. 